Published in final edited form in Biological Chemistry, 397 (2): 111-123 at https://doi.org/10.1515/hsz-2015-0229.

\title{
Crystal structure of cleaved vaspin (serpinA12)
}

\section{Jan Pippel ${ }^{1}$, E. Bartholomeus Kuettner ${ }^{1}$, David Ulbricht ${ }^{2}$, Jan Daberger ${ }^{2}$, Stephan Schultz ${ }^{2}$, John T. Heiker ${ }^{2 *}$ and Norbert Sträter ${ }^{*}$}

${ }^{1}$ Center for Biotechnology and Biomedicine, Institute of Bioanalytical Chemistry, University of Leipzig, 04103 Leipzig, Germany

${ }^{2}$ Institute of Biochemistry, Faculty of Biosciences, Pharmacy and Psychology, University of Leipzig, 04103 Leipzig, Germany

Running title: Structure of cleaved vaspin

*Corresponding authors:

John T. Heiker

Institute for Biochemistry

University of Leipzig

Brüderstr. 34

04103 Leipzig

Germany

Phone: +49 3419736705

Fax: $\quad+493419736909$

jheiker@uni-leipzig.de

\author{
Norbert Sträter \\ Institute of Bioanalytical Chemistry \\ Center for Biotechnology and Biomedicine \\ University of Leipzig \\ Deutscher Platz 5 \\ 04103 Leipzig \\ Germany \\ Phone: +49 3419731311 \\ Fax: $\quad+493419731319$ \\ strater@bbz.uni-leipzig.de
}




\begin{abstract}
The adipokine vaspin (serpinA12) is mainly expressed in white adipose tissue and exhibits various beneficial effects on obesity-related processes. Kallikrein 7 is the only known target protease of vaspin and is inhibited by the classical serpin inhibitory mechanism involving a cleavage of the reactive center loop between P1 (M378) and P1' (E379). Here, we present the X-ray structure of vaspin, cleaved between M378-E379. We provide a comprehensive analysis of differences between the uncleaved and cleaved forms in the shutter, breach, and hinge regions as well as helix $F$ with relation to common molecular features underlying the serpin inhibitory mode. Furthermore, we point out differences towards other serpins and provide novel data underlining the remarkable stability of vaspin. We speculate that the previously reported $\mathrm{FKGx}_{1} \mathrm{Wx}_{2} \mathrm{x}_{3}$ motif in the breach region may play a decisive role in determining the reactive center loop configuration in the native vaspin state and might contribute to the high thermostability of vaspin. Thus, this structure may provide a basis for future mutational studies.
\end{abstract}

Keywords: cleaved serpin; kallikrein 7; reactive center loop; vaspin; x-ray structure 


\section{Introduction}

The visceral adipose tissue-derived serine protease inhibitor (vaspin; uniprot accession number: Q8IW75) was first identified in white adipose tissue of the Otsuka Long-Evans Tokushima Fatty (OLETF) rat type-2 diabetes model where it led to improved insulin sensitivity and glucose tolerance upon administration (Hida et al., 2005). Also, under a high fat diet an improved glucose tolerance together with reduced weight gain was observed in vaspin transgenic mice (Nakatsuka et al., 2012). In humans, vaspin mRNA and serum levels are associated with parameters of obesity and insulin resistance (Klöting et al., 2006; Youn et al., 2008). Based on such findings, it has been hypothesized that vaspin could function as a compensatory, anti-diabetic and anti-atherogenic protein in obesity related disorders such as insulin resistance or diseases of the cardiovascular system (Heiker, 2014). Thus, vaspin constitutes a promising drug target with various fields of applications in metabolic and atherogenic diseases induced by overweight and obesity (Blüher, 2012). Vaspin belongs to the serpin family (serpinA12) and kallikrein 7 (KLK7) is the only known target protease of vaspin (Heiker et al., 2013; Ulbricht et al., 2015). The mentioned beneficial effects on glucose tolerance in mice can be ascribed to the inhibitory activity of vaspin (Heiker et al., 2013). Furthermore, for both proteins, a role in psoriasis, a chronic skin inflammation often related to obesity, has been demonstrated (Eissa and Diamandis, 2008; Saalbach et al., 2012; Schultz et al., 2013). Together, these findings highlight the pathophysiological relevance of vaspin and KLK7. Thus, a detailed structural understanding of the inhibitory action of vaspin towards KLK7 may contribute to the pharmaceutical intervention or modulation of vaspin activity as well as to a profound understanding of underlying specificity.

Inhibitory serpins form covalent complexes with serine proteases under incorporation of the reactive center loop (RCL) into their central $\beta$-sheet A (Engh et al., 1989; Patston et al., 1991). The serpin RCL comprises the cleavage site(s) for the target protease(s) and is mostly flexible in the 3 
native state of inhibitory serpins. Upon cleavage of the RCL, a covalent ester bond is formed between S195 of the respective protease and the backbone carbonyl of the serpin P1 residue. Prior to hydrolysis and release of the protease, the RCL inserts into $\beta$-sheet A. Thereby the protease is translocated by $\sim 70 \AA$ and altered inactive by conformational distortion of the active site (Huntington et al., 2000; Dementiev et al., 2006). The thermodynamic driving force of this process lies within the intrinsic metastability of the native state which energetically favors the formation of the RCL-inserted state (Huber and Carrell, 1989; Ryu et al., 1996; Lee et al., 2000). In consequence, this "poised ready" conformation (Harrop et al., 1999) bears the risk of unintended serpin inactivation due to latency transition (protease independent incorporation of the RCL: Mottonen et al., 1992; Na and Im, 2007) or polymerization (Davis et al., 1999; Yamasaki et al., 2008). In both, the latent and polymerized state, the RCL is usually inaccessible for protease(s) rendering the serpin inactive. Different mechanisms of polymerization have been proposed. The loop-sheet mechanism is based on RCL insertion of the donor serpin molecule as strand 4A (s4A) into $\beta$-sheet A of the acceptor serpin molecule (Chang et al., 1997). Other mechanisms are based on crystal structure data and involve more extended domain swapping. For the s4A/5A mechanism the RCL and further $\mathrm{C}$-terminal amino acids form both s4A and the neighboring s5 A of the central $\beta$-sheet A of the acceptor serpin molecule (Yamasaki et al., 2008). For PAI-1, another polymerization mechanism was observed in which the RCL forms a new strand s7A on the edge of $\beta$-sheet A from a neighboring molecule. In this mode, only half of the molecules "donate" their RCL, whereas for the other half, the RCL remains exposed and potentially accessible (Sharp et al., 1999; Zhou et al., 2001). In vivo, polymerization most likely features a swap of major C-terminal domains. These involve strands s1C, s4B and s5B while the RCL is incorporated into the own central $\beta$-sheet $A$, as in the latent transition (Yamasaki et al., 2011). On that note, for vaspin we have previously reported 
a remarkable thermostability, as only high temperatures were able to induce polymerization (Ulbricht et al., 2015). We also found no indications for a tendency towards the latent transition and prolonged storage at $4^{\circ} \mathrm{C}$ does not alter activity significantly. The molecular basis and physiologic impact of this characteristic are not yet understood.

Due to the sophisticated purification and crystallization procedures, only two crystal structures of covalent serpin-protease complexes have been published (Huntington et al., 2000; Dementiev et al., 2006). As for vaspin, so far only crystal structures of the wildtype and mutants in the native, uncleaved state are available and are providing little information of its behavior in the covalent complex (Heiker et al., 2013; Ulbricht et al., 2015). But, when attacking serpin RCLs, some protease molecules escape the inhibitory pathway releasing a cleaved substrate-serpin. To attain the hyperstable serpin conformation, the cleaved RCL is still inserted into the central $\beta$-sheet A, and previous structural analyses demonstrated that folds of the cleaved state and of the covalent complex with the protease are highly similar (Huntington et al., 2000; Dementiev et al., 2006). Thus, crystal structures of cleaved serpins provide valuable structural insight into the specific serpin inhibition mechanism where crystal structures of the covalent complex are not available. Here, we present the X-ray structure of cleaved vaspin, and an in depth comparison with the native state and other cleaved as well as native serpin structures with a focus on changes that accompany the transition from the native to the cleaved state as well as on vaspin stability.

\section{Results and Discussion}

Crystallization and structure determination - Prior to crystallization, the intact RCL of purified native vaspin was confirmed via HPLC, SDS-PAGE and complex formation experiments with its target protease KLK7 (Heiker et al., 2013). Thus, cleavage occurred during the crystallization 
process, either by unintended protease contamination in the crystallization drop or spontaneously, as also reported for the Drosophila melanogaster Serpin 42 Da (Ellisdon et al., 2014).

Crystals of cleaved vaspin contain two monomers in the asymmetric unit. The final model comprises 372 (chain A) and 371 (chain B) residues with only three amino acids adjacent to the observed cleavage site missing (M378 for chain A, E379-T380 for chain B) - most likely due to increased flexibility.

Comparison of the overall folds of the native and cleaved vaspin crystal structures - Native vaspin exhibits the classical serpin structure with the exposed RCL (Figure 1A) (Heiker et al., 2013). The intact RCL at the top of vaspin, comprising residues E362 to M378, is in large parts not defined by electron density (in the classical view depicted in Figure 1). This conformation is equivalent to that of inhibitory serpins and corresponds to a high-energy or metastable state (Huber and Carrell, 1989; Ryu et al., 1996; Lee et al., 2000). In the X-ray structure of cleaved vaspin, the central $\beta$-sheet is expanded from five to six $\beta$-strands by incorporation of the RCL as central strand s4A - the hallmark of inhibitory serpins that have been cleaved within the RCL (Figure 1A, 1B) (Huntington et al., 2000; Dementiev et al., 2006). An alignment by main-chain atoms s5A and s6A as in Jensen et al. yields a better superposition of the central $\beta$-sheet and nearby elements, while the other parts move further with the insertion of the s4A strand (Supplementary Figure S1). A comparison to other crystal structures of cleaved human inhibitory serpins (Table 1) demonstrates a high similarity of the RCL-cleaved fold with low root mean square deviations (rmsd) of $1.4-$ $2.1 \AA$, despite low sequence similarities among these serpins (ranging from $24-43 \%$ sequence identity).

\section{Table 1 should be positioned here}


Vaspin is cleaved by KLK7 between P1 M378 and P1' E379 (Heiker et al., 2013). In the crystallized cleaved vaspin (chain B), the electron density of M378 is relatively well defined and there is no density visible after this residue (Figure 1B, bottom detail). The post cleavage site P1'P2' residues E379 and T380 are disordered and were not modeled (Figure 1B, upper detail). Due to crystal contacts, these two residues are well defined in chain A with E379 representing the Cterminal end of the cleavage site, while the N-terminal M378 could not be modeled in this chain. Assuming that the crystals did not form from a heterogeneous mixture of different RCL cleavage sites, these findings confirm the cleavage site between M378 and E379.

Changes in the shutter region - The shutter region is located in the middle of the protein and comprises various conserved amino acids from s6B, helix B (hB) as well as $\beta$-sheet A which are crucial for protein stability and, more importantly, control the opening of $\beta$-sheet A which represents a key process of the serpin inhibitory mechanism (Stein and Carrell, 1995; Whisstock et al., 2000; Zhou et al., 2003). Particularly, the comprehensive hydrogen bond network and the packing between the highly conserved residues $\mathrm{S} 75, \mathrm{~S} 78$ (both $\mathrm{hB}$; from the classical serpin view, $\mathrm{hB}$ is located on the back side of sheet A), N206 (s3A), and H354 (s5A) has been shown to be of great importance for the inhibitory process (Harrop et al., 1999; Whisstock et al., 2000; Ellisdon et al., 2014) (Figure 2A). Therefore, mutations in this domain have been linked to polymerization and clinical diseases in various serpins (Seyama et al., 1991; Millar et al., 1994; Gooptu et al., 2000; Lomas and Carrell, 2002). In vaspin, the amino acid composition of the shutter domain is identical to the consensus sequence for human inhibitory serpins (Figure 3). With hydrogen bonds between S75, S78, N206 and H354, complemented by a hydrogen bond between N206 and N136 (s2A), the shutter region of native vaspin shows no signs for destabilization that could be linked to 7 
polymerization tendencies such as observed for mutations in $\alpha_{1}$-antitrypsin $\left(\alpha_{1}\right.$ PI, S53F (S75 in vaspin), Millar et al., 1994) or in neuroserpin (S52R (S78 in vaspin), Takao et al., 2000). Noteworthy, in PAI-1, the shutter domain composition is significantly different (S58, G61, D118, N190 and Q345; Figure 3), but if adapted to the consensus sequence (e.g. G61S or Q345H), the half-life of Plasminogen activator inhibitor 1 (PAI-1) was dramatically reduced (Kirkegaard et al., 1999; Hansen et al., 2001). Thus, for some specific serpins, other shutter region compositions occur, which have similar stabilizing effects.

Upon cleavage of the RCL and insertion into the central $\beta$-sheet A, s3A is replaced by the new strand s4A. As a result, N206 (s3A) is substituted by the likewise conserved T371 (s4A, P8) which establishes hydrogen bonds to H354 and S78 (Figure 2B, 3). Thus, despite the significant conformational change that takes place in the shutter domain during transition from the native to the cleaved state, a comprehensive hydrogen bond network within this region, comparable to other serpins, is reconstituted after insertion of the new strand in the cleaved form of vaspin.

Changes within the breach region - The stressed, metastable character of native serpins is a requirement for the unique mode of protease inhibition but simultaneously increases the risk for misfolding, latency transition, or polymerization (reviewed in Belorgey et al., 2007). Particularly the breach region has been shown to play an important regulatory role in stabilizing the high-energy serpin conformation while providing sufficient structural flexibility for the serpin inhibitory mechanism to proceed (Whisstock et al., 2000; Pearce et al., 2007). It is located at the top of the central $\beta$-sheet and is the point of initial insertion of the RCL as the additional strand of $\beta$-sheet A. The breach region comprises a number of conserved residues from strand $\mathrm{s} 3 \mathrm{~A}$ as well as from the top of s5A, s2B, s3B and s4B (Whisstock et al., 2000; Khan et al., 2011). In native vaspin, the breach region resembles a 'partially opened zipper' with a water-filled void between s3A and s5A 8 
for the incorporation of the RCL-derived s4A (Figure 4A). This is observed in various other nativestate human inhibitory serpins (e.g. neuroserpin (pdb code:3F5N (Ricagno et al., 2009)), Protein C inhibitor (PCI, pdb code: 2OL2 (Li et al., 2007)), $\alpha_{1}$ PI (pdb code: 3CWL (Pearce et al., 2008)), PAI-1 (pdb codes: 1DVM, 3Q03 (Stout et al., 2000; Jensen et al., 2011)), and PAI-2 (pdb code: 1BY7 (Harrop et al., 1999))). It is assumed to facilitate incorporation of the additional $\beta$-strand s4A upon cleavage of the RCL (Harrop et al., 1999; Li et al., 1999). Harrop et al. attribute the $\beta$-strand separation to the steric effect of the large side chains of Y264 and W214, the latter residue being part of a conserved motif discussed below (Figure 3, Figure 4) (Harrop et al., 1999). In the native vaspin structure, this conformation is further stabilized by strong hydrogen bonds between the side chains of the conserved R211 (s3A) and E357 (s5A) which would - to stay with the zipper analog - correspond to the position of the zip slider. E357 (s5A) is additionally hydrogen bonded by H312 (s6A). Beneath the side chain R211-H312-E357 axis, the typical interactions of parallel $\beta$-strands are observed, altogether resulting in a very firm interaction of s3A and s5A. Thus, in native vaspin, the breach region exhibits various interactions which effectively stabilize this state.

Upon insertion of the RCL into $\beta$-sheet A between s3A and s5A, a full antiparallel $\beta$-sheet with six $\beta$-strands is formed (Figure 4B). Hence, in this conformation, the above mentioned interactions between these two strands are displaced and the entire $\beta$-sheet is stabilized by the common hydrogen bond network and only one side chain interaction between E357 and T314 is observed in this conformation within s5A and s6A (Figure 4B). Y264 forms a hydrogen bond with T365 (P14) in the cleaved conformation. Both, Y264 and T365 (or the equivalent pair tyrosine/serine) are conserved to $\sim 87 \%$ in all inhibitory serpins and the interaction has been suggested an important determinant of RCL insertion in PAI-2 and LEI (Jankova et al., 2001; Saunders et al., 2001). Also, this important hydrogen bond appears in all of the here mentioned cleaved serpin X-ray structures (Table 1). In line with these observations, the mutations T345R in $\alpha_{1}$-antichymotrypsin $\left(\alpha_{1} \mathrm{ACT}\right.$, 9 
Lukacs et al., 1998a), and T356P in PAI-1 (Gils et al., 1996) resulted in non-inhibitory serpins. Also in vaspin, the T365R mutant is a non-inhibitory variant cleaved by KLK7 in vitro (Heiker et al., 2013). Interestingly, the X-ray structure of T345R $\alpha_{1} \mathrm{ACT}$ mutant revealed that RCL insertion is still occurring, but the strand has turned around and the bulky arginine side chain faces away from the hydrophobic serpin core (Lukacs et al., 1998a). This process slows down RCL insertion and allows for complete cleavage and release of the protease. Comparison of thermal unfolding of protease-cleaved T365R vaspin to the intact serpin also revealed a substantial increase in stability, clearly suggesting that also in vaspin the T365R mutation does significantly slow down, but does not prevent RCL insertion (Figure 5A). In line with these findings, heat-induced polymerization is observed and comparable to wild type vaspin (Ulbricht et al., 2015) for the T365R mutant, while cleaved T365R vaspin remains in solution as a monomeric molecule even at $90^{\circ} \mathrm{C}$ (Figure 5B).

Interactions of the breach region with hinge region residues - Further stabilization of the native vaspin state involves hydrogen bonds and electrostatic interactions of the breach region with hinge region residues of the RCL (D362-G370, P17-P9) by which the RCL is held in a "poised-ready" position (Harrop et al., 1999). A prominent feature of this region is a surface groove, composed of R213-F218 from the loop connecting s3A and s4C, which embeds residues R363-E366 (P16-P13) of the RCL hinge region involving many hydrogen bond interactions (Figure 4A). A number of breach region residues are conserved among human serpins, most notably the $\mathrm{FKGx}_{1} \mathrm{Wx}_{2} \mathrm{X}_{3}$ motif (Whisstock et al., 2000). This motif might even be extended to FKGx $1 \mathrm{Wx}_{2} \mathrm{X}_{3} \mathrm{X}_{4} \mathrm{~F}$, according to the consensus sequence (conversation $>70 \%$ ) of human inhibitory serpins (Figure 3). With $85 \%$ sequence identity, residues FKG and W are even more conserved (Whisstock et al., 2000). From the literature, only little is known about the motif and its function is yet to be elucidated. In vaspin, the motif is slightly different with $\mathrm{FRAx}_{1} \mathrm{~W}_{2} \mathrm{X}_{3} \mathrm{X}_{4} \mathrm{~F}$ (residues 214-218) but the main properties of 10 
the residues are preserved. W214 is positioned at the bottom of the groove in line with the hydrophobic residues F210, F218 and Y264. These four large aromatic side chains form a stable ground below the RCL hinge region in the cleaved and uncleaved states and contribute to core stability of the serpin fold in this critical breach region. W214 furthermore forms a hydrogen bond with the carbonyl oxygen of D361, an interaction that has been observed also for all native as well as cleaved serpin structures listed in this study (Figure 4A, B). Thus, this hydrogen bond might constitute an important feature for inhibitory serpins as also suggested by others (Harrop et al., 1999; Li et al., 1999; Blouse et al., 2003). However, mutations of W214 had diverging effects in different serpins. In PAI-1, exchange of the respective tryptophan W175 to phenylalanine led to altered inhibition kinetics and stabilized the protein against latency (Blouse et al., 2003). Since the packing of the W175F PAI-1 breach region is not affected by the amino acid replacement, these effects are proposed to result from an increased activation energy for RCL insertion (pdb code: 3Q02; Jensen et al., 2011). In contrast, in $\alpha_{1}$ ACT the same mutation at W194 increased the risk of polymerization which was pinned on the altered hydrogen bonding pattern that stabilizes the preinserted RCL conformation in native $\alpha_{1} \mathrm{ACT}$ (Pearce et al., 2007). Together, all these data demonstrate the key role of this particular residue.

The R213 ( $\left.\mathrm{x}_{1}\right)$ and E217 ( $\left.\mathrm{x}_{4}\right)$ residues of the motif form the walls of the narrow groove of the breach region in the native state and P15 RCL-residue G364 is directly positioned between R213 and E217 (Figure 4A). These positions are not conserved in human serpins but are mostly occupied by other polar and bulky side chains skirting the groove (Figure 3). Structural features are very similar in the uncleaved human $\alpha_{1}$-antithrombin ( $\left.\alpha_{1} \mathrm{AT}\right)$ structure, but there the groove is occupied by the side chain of K343 and the RCL is winded around (pdb code: 3CWL (Pearce et al., 2008).

In the cleaved state of vaspin, the groove is not present anymore with the now interacting side chains of E217 and R213 closing the gap (Figure 4B). The strictly conserved G364 (P15) of the 11 
new $\beta$-strand s4A is positioned in close proximity to the side chains of W214 and Y264. Larger side chains than that of glycine would clash with the W214 indole group in the cleaved state and with R213 ( $\mathrm{x}_{1}$ of the aforementioned motif) and E217 ( $\left.\mathrm{x}_{4}\right)$ in the native state (Figure 4A). Indeed, substitution of this glycine by proline in PAI-1 resulted in a substrate-like behavior of the serpin, though RCL incorporation was still observed (Gils et al., 1996).

The second strictly conserved residue of the breach region is E362 (Figure 3). It interacts with R310, both in the cleaved and uncleaved state of vaspin (Figure 4A, B). R310 is replaced mostly by lysine or occasionally by a glutamine (Figure 3). The high degree of conservation of E362 can be explained from its crucial function in anchoring the end of s5A and simultaneously forming a hinge point for formation and insertion of s4A (Harrop et al., 1999). In the Z-variant of $\alpha 1 \mathrm{AT}$, latency, misfolding, and polymerization is increased via the natural occurring mutation of glutamate to lysine at that position (E342K, SNP number: Rs28929474) indicating the high importance of this conserved salt bridge for native state serpin stability and folding (Jeppsson, 1976; Lomas et al., 1992). This mutation accounts for $95 \%$ of all $\alpha_{1} \mathrm{AT}$ deficiencies and is associated with various physiological diseases of the liver such as cirrhosis or hepatocellular carcinoma (Eriksson et al., 1986; reviewed in Stoller and Aboussouan, 2012).

Another potentially important residue adjacent to E362 is D361 forming a salt bridge with R363 in native vaspin and possibly prevents further pre-insertion of the RCL into the upper void between s3A and s5A (Figure 4A). In the cleaved state, D361 is involved in stabilizing the turn of the new $\beta$-strand by forming hydrogen bonds with the NH backbone atoms of R363 and G364 (Figure 4B). In other serpins, it is replaced by polar residues (Figure 3) that are involved in similar hydrogen bonding interactions such as N345 in neuroserpin (pdb codes: 3F02, 3F5N, 3FGQ (Ricagno et al., 2009; Takehara et al., 2009). Overall, the sum of these comprehensive interactions in the native state is likely to impede formation of the latent state or polymerization in vaspin. In line with these 12 
observations, we have previously demonstrated vaspins thermostability and reluctance to form polymers (Ulbricht et al., 2015). In addition, we here tried to induce the latent transition by incubating vaspin under high temperatures using citrate as a stabilizing agent. Citrate has been previously used to suppress heat-induced polymerization and enabled the latent transition of other serpins, such as $\alpha_{1}$ PI and $\alpha_{1}$ AT (Lomas et al., 1995; Wardell et al., 1997; Pearce et al., 2008) While the addition of citrate resulted in suppression of polymerization (Figure $5 \mathrm{C}$ and $\mathrm{D}$, top panel), the persistent monomeric vaspin remained active (i.e. able to complex KLK7) even after incubation at very high temperatures $\left(3 \mathrm{~h}\right.$ up to $80^{\circ} \mathrm{C}$ ) or for prolonged time $\left(15 \mathrm{~h}\right.$ at $75^{\circ} \mathrm{C}$ ) (Figure $5 \mathrm{C}$ and $\mathrm{D}$, bottom panel).

The environment of the inserted $\beta$-strand $\mathbf{s} 4 \mathbf{A}$ - The hinge region of the inserted $\beta$-strand s4A is largely conserved among serpins with the consensus sequence GTEAAAx 1 T (Table 1). The important role of the first threonine in vaspin, T365, has already been discussed above. Mutations in this region all negatively affect inhibitory activity of the serpin. One of many examples is the naturally occurring P10 mutant A384P for $\alpha_{1}$ AT (Molho-Sabatier et al., 1989; Perry et al., 1989). A P10 proline resulted in complete loss of activity in $\alpha_{1}$ AT and $\alpha_{1}$ PI (Caso et al., 1991; Hopkins et al., 1993) and mutation of P10 A369P in vaspin also yielded a non-inhibitory variant (Heiker et al., 2013). Studies on G349P in ${ }_{1}$ PI suggested that a P10 proline does not affect initial protease-serpin interaction and thus slows down RCL insertion but does not prevent formation of the full antiparallel $\beta$-sheet (Hopkins et al., 1993). A clear gain in stability after protease cleavage was observed for the A369P mutant of vaspin, again supporting slowed but still occurring RCL insertion underlying the substrate nature of these hinge region mutants (Figure 5A). In comparison to the T365R mutant in vaspin, introduction of a proline at the P10 position seems to slightly destabilize the relaxed (RCL-inserted) conformation, as a minor transition is observed at above 13 
$90^{\circ} \mathrm{C}$ and heat-induced polymers are observed for the cleaved A369P mutant after incubation at these temperatures (Figure 5B).

The last residue of this sequence is T371, which interacts with the side chains of S78 and H354 of the shutter domain as discussed above (Figure 2). The following six residues of the RCL vary significantly between serpins and do not exhibit notable interactions. The side chains of G372 and A373 have narrow apolar environments and Q374 shows large variation in other serpin structures and it is hydrogen bonded to T200, which is well conserved (Figure 3). The P1 and P1' residues are primary determinants of a serpins specificity, whereas P3, P2, P2' and P3' are of less importance for the selectivity (Jallat et al., 1986; Gettins, 2002). In the cleaved vaspin structure residues $\mathrm{P} 1$ to $\mathrm{P} 3$ are located in an environment with low constraints and are solvent accessible, which is a common feature for these residues in structures of cleaved serpins (Figure 1B, bottom detail). Notably, KLK7 has a strong preference for Y, F, M or A at S1 and R or K at S1' and S2' (Debela et al., 2006; Oliveira et al., 2015). However, mutation of the P1 position, M378Y, does not considerably improve KLK7 inhibition $\left(k_{a}=22.2 \pm 1.4 \mathrm{mM}^{-1} \cdot \mathrm{s}^{-1} \mathrm{vs} 12.3 \pm 0.3 \mathrm{mM}^{-1} \cdot \mathrm{s}^{-1}\right.$ for the wild type). Thus, the most decisive residue in the vaspin RCL is the P1' $\mathrm{E} 379$, as this clearly is not a preferred cleavage site for KLK7. With E379 at position P1', vaspin does not exhibit a preferred RCL sequence for KLK7 inhibition and we recently proposed that exosite interactions play an important role enabling KLK7 inhibition with vaspins R302 playing a key role to offset the detrimental cleavage site (Ulbricht et al., 2015).

Conclusions - Serpins are effective protease inhibitors with specificities for a wide range of proteases. The inhibition follows a suicide-substrate mechanism and involves extensive domain rearrangements within the vaspin molecule. The structure of cleaved vaspin and the comparison to its native structure as well as to other serpins in both states provides insight into pronounced 14 
molecular features that may play important roles in the stabilization of the native state of vaspin. On the molecular level, particularly extensive interactions of the RCL hinge region residues with the breach domain seem of importance for the stability of vaspin in the native state. This involves numerous hydrogen bonds and two salt bridges as well as a pronounced groove formed by the conserved motif $\mathrm{FRAx}_{1} \mathrm{Wx}_{2} \mathrm{X}_{3} \mathrm{X}_{4} \mathrm{~F}$ (residues 214-218) of the breach region. The walls of this narrow groove are formed by R213 (x1) and E217 (x4) with G364 (P15) being positioned directly between them. Altogether, these interactions result in rather constrained RCL hinge region residues R363E366 (P16-P13) which on one hand might prevent latency and/or polymerization and, on the other hand, hold the overall RCL in a 'poised-ready' (Harrop et al., 1999) position for the inhibitory mechanism to proceed. Complementing previous data on heat-induced polymerization, we here show, that using citrate to suppress polymerization, vaspin remained in the active conformation at temperatures up to $80^{\circ} \mathrm{C}$ or prolonged incubation at $75^{\circ} \mathrm{C}$. Thus, vaspin represents a model protein for the investigations of how serpins effectively stabilize their native fold. Prominent residues addressed and discussed here can serve as targets for future mutagenesis studies on the molecular basis for the high stability of vaspin in the native state. Beyond that, the physiologic relevance of this characteristic is unclear and it remains unknown, if latent or polymerized vaspin are present in vivo.

\section{Materials and methods}

Generation of recombinant vaspin - Recombinant expression and purification of vaspin and mutants was carried out as previously described (Ulbricht et al., 2015). Briefly, N-terminal decahistidine-tagged recombinant vaspin was expressed in E. coli and purified via immobilized metal ion affinity chromatography and gel filtration using a HiLoad 16/60 Superdex 200 column on an ÄKTA protein purification system (all from GE Healthcare, Freiburg, Germany). Purified 15 
proteins were analyzed by RP-HPLC, SDS-PAGE, MALDI-ToF MS and stored at $4{ }^{\circ} \mathrm{C}$ until further use. The rate of inhibition for vaspin mutant M378Y was determined using a discontinuous assay as previously described (Heiker et al., 2013). Cleaved forms of T365R and A369P were generated by incubation with $\operatorname{KLK} 7$ (1:20 molar ratio of protease to serpin) over night at room temperature. Complete cleavage was ascertained by SDS-PAGE and MALDI-ToF MS.

Crystallization, X-ray data collection and structure determination - For crystallization, gel filtration peak fractions were pooled and concentrated to $12 \mathrm{mg} / \mathrm{ml}$. In a hanging-drop vapor diffusion setup at $292 \mathrm{~K}, 1 \mu \mathrm{l}$ protein and $1 \mu \mathrm{l}$ crystallization buffer were mixed and equilibrated against $0.5 \mathrm{ml}$ of crystallization buffer as reservoir solution (supplementary Table1). The analyzed crystals were directly frozen in liquid nitrogen. X-ray data collection was carried out at $100 \mathrm{~K}$ using a wavelength of $0.91841 \AA$ on beamline 14.1 of the Berlin Synchrotron (BESSY, Berlin, Germany) equipped with a MARMosaic-CCD detector $(225 \mathrm{~mm})$ (MARRESEARCH, Norderstedt, Germany). The diffraction data were indexed, integrated and scaled with XDS (Kabsch, 2010) and aimless (Evans and Murshudov, 2013) of the CCP4 suite (Collaborative Computational Project, Number 4, 1994). Coordinates of residues 77-212, 220-310, 378-408 and 311-360 of wildtype vaspin (pdb: 4IF8) were used as search models for molecular replacement under PHASER (McCoy et al., 2007). Coordinates of the best solution were taken as starting model for rigid body refinement using REFMAC5 (Murshudov et al., 1997; Murshudov et al., 2011). The model was further improved by iterative cycles of TLS refinement using REFMAC5 (Murshudov et al., 1997; Murshudov et al., 2011) as well as PHENIX (Adams et al., 2010) and manual rebuilding with COOT (Emsley et al., 2010). TLS groups were determined using the TLSMD web server (Painter and Merritt, 2006a, 2006b). Structures were validated by MOLPROBITY (Chen et al., 2010). Final structure building and interpretation was aided by feature enhanced maps 16 
calculated with PHENIX (Adams et al., 2010; Afonine et al., 2015). Final coordinates and structure factors have been deposited in the Protein Data Bank (Berman et al., 2000) under accession code 5EI0 and relevant crystallographic data is specified in supplementary Table 1. Secondary structure elements were assigned using the DSSP web server (Kabsch and Sander, 1983; Touw et al., 2015). Figures were prepared using PyMOL (www.pymol.org). RMSD values towards other cleaved serpin structures were calculated using the DALI server (Holm and Rosenström, 2010). Sequences were aligned with the Clustal Omega web server at EMBL-EBI (Goujon et al., 2010; Sievers et al., 2011). The alignment Figure was generated with the ESPript 3.0 web server after manual editing (Robert and Gouet, 2014). As vaspin chain B exhibits the most complete electron density, it has been used for Figures and analysis unless otherwise stated. All residue numbers used in this study refer to the vaspin numbering if not stated otherwise. The annotation of positions of RCL residues in this study follows the nomenclature of Schechter and Berger (Schechter and Berger, 1967).

\section{Circular dichroism spectroscopy, temperature-induced polymerization and complex} formation analysis - Circular dichroism (CD) spectra were recorded using $1 \mathrm{~mm}$ quartz cuvettes (Hellma, Jena, Germany) on a J-715 spectropolarimeter (Jasco, Tokyo, Japan) equipped with a Peltier-type temperature control system. Spectra were acquired as previously described (Ulbricht et al., 2015). For polymerization, vaspin $(0.3 \mu \mathrm{g} / \mu \mathrm{l})$ was heated for $3 \mathrm{~h}$ or $15 \mathrm{~h}$ in Tris buffer (20 $\mathrm{mM}, \mathrm{pH} 8.5)$ at temperatures ranging from $60-85^{\circ} \mathrm{C}$ with or without the addition of $850 \mathrm{mM}$ citrate and $500 \mathrm{mM} \mathrm{NaCl}$ as indicated. Vaspin-KLK7 complex formation after heating was analyzed after cooling on ice before incubation with KLK7 for 30 min (3:1 molar ratio of protease to serpin). Polymerization and complex formation were analyzed by SDS-PAGE as previously described (Ulbricht et al., 2015). 


\section{Acknowledgements}

The vaspin expression plasmid was kindly provided by Dr. J. Wada (Department of Medicine and Clinical Science Okayama University Graduate School of Medicine, Okayama, Japan). We thank Susanne Moschuetz and Antje Keim for help with purification and crystallization. This work was supported by the European Union and the Free State of Saxony (J.T.H.) and by the Deutsche Forschungsgemeinschaft SFB1052 “Obesity Mechanisms” (C4 N.S., C7 J.T.H.). The authors thank the Joint Berlin MX-Laboratory at BESSY II, Berlin, Germany, for beam time and assistance during synchrotron data collection as well as the Helmholtz Zentrum Berlin for travelling support. 


\section{References}

Adams, P.D., Afonine, P.V., Bunkóczi, G., Chen, V.B., Davis, I.W., Echols, N., Headd, J.J., Hung, L.-W., Kapral, G.J., Grosse-Kunstleve, R.W., McCoy, A.J., Moriarty, N.W., Oeffner, R., Read, R.J., Richardson, D.C., Richardson, J.S., Terwilliger, T.C., and Zwart, P.H. (2010). PHENIX: a comprehensive Python-based system for macromolecular structure solution. Acta Crystallogr, Sect D: Biol Crystallogr 66, 213-221.

Afonine, P.V., Moriarty, N.W., Mustyakimov, M., Sobolev, O.V., Terwilliger, T.C., Turk, D., Urzhumtsev, A., and Adams, P.D. (2015). FEM: feature-enhanced map. Acta Crystallogr, Sect D: Biol Crystallogr 71, 646-666.

Baumann, U., Huber, R., Bode, W., Grosse, D., Lesjak, M., and Laurell, C.B. (1991). Crystal structure of cleaved human alpha 1-antichymotrypsin at 2.7 A resolution and its comparison with other serpins. J Mol Biol 218, 595-606.

Belorgey, D., Hägglöf, P., Karlsson-Li, S., and Lomas, D.A. (2007). Protein misfolding and the serpinopathies. Prion 1, 15-20.

Berman, H.M., Westbrook, J., Feng, Z., Gilliland, G., Bhat, T.N., Weissig, H., Shindyalov, I.N., and Bourne, P.E. (2000). The Protein Data Bank. Nucleic Acids Res 28, 235-242.

Blouse, G.E., Perron, M.J., Kvassman, J.-O., Yunus, S., Thompson, J.H., Betts, R.L., Lutter, L.C., and Shore, J.D. (2003). Mutation of the highly conserved tryptophan in the serpin breach region alters the inhibitory mechanism of plasminogen activator inhibitor-1. Biochemistry 42, 12260 12272 .

Blüher, M. (2012). Vaspin in obesity and diabetes: pathophysiological and clinical significance. Endocrine 41, 176-182.

Caso, R., Lane, D.A., Thompson, E.A., Olds, R.J., Thein, S.L., Panico, M., Blench, I., Morris, H.R., Freyssinet, J.M., and Aiach, M. (1991). Antithrombin Vicenza, Ala 384 to Pro (GCA to CCA) mutation, transforming the inhibitor into a substrate. Br J Haematol 77, 87-92.

Chang, W.S., Whisstock, J., Hopkins, P.C., Lesk, A.M., Carrell, R.W., and Wardell, M.R. (1997). Importance of the release of strand $1 \mathrm{C}$ to the polymerization mechanism of inhibitory serpins. Protein Sci 6, 89-98.

Chen, V.B., Arendall, W.B., Headd, J.J., Keedy, D.A., Immormino, R.M., Kapral, G.J., Murray, L.W., Richardson, J.S., and Richardson, D.C. (2010). MolProbity: all-atom structure validation for macromolecular crystallography. Acta Crystallogr, Sect D: Biol Crystallogr 66, 12-21.

Collaborative Computational Project, Number 4 (1994). The CCP4 suite: programs for protein crystallography. Acta Crystallogr, Sect D: Biol Crystallogr 50, 760-763.

Davis, R.L., Shrimpton, A.E., Holohan, P.D., Bradshaw, C., Feiglin, D., Collins, G.H., Sonderegger, P., Kinter, J., Becker, L.M., Lacbawan, F., Krasnewich, D., Muenke, M., Lawrence, D.A., Yerby, M.S., Shaw, C.M., Gooptu, B., Elliott, P.R., Finch, J.T., Carrell, R.W., and Lomas, 
D.A. (1999). Familial dementia caused by polymerization of mutant neuroserpin. Nature 401, 376379.

Debela, M., Magdolen, V., Schechter, N., Valachova, M., Lottspeich, F., Craik, C.S., Choe, Y., Bode, W., and Goettig, P. (2006). Specificity profiling of seven human tissue kallikreins reveals individual subsite preferences. J Biol Chem 281, 25678-25688.

Dementiev, A., Dobó, J., and Gettins, P.G.W. (2006). Active site distortion is sufficient for proteinase inhibition by serpins: structure of the covalent complex of alpha1-proteinase inhibitor with porcine pancreatic elastase. J Biol Chem 281, 3452-3457.

Dewilde, M., Strelkov, S.V., Rabijns, A., and Declerck, P.J. (2009). High quality structure of cleaved PAI-1-stab. J Struct Biol 165, 126-132.

Eissa, A., and Diamandis, E.P. (2008). Human tissue kallikreins as promiscuous modulators of homeostatic skin barrier functions. Biol Chem 389, 669-680.

Ellisdon, A.M., Zhang, Q., Henstridge, M.A., Johnson, T.K., Warr, C.G., Law, R.H., and Whisstock, J.C. (2014). High resolution structure of cleaved Serpin 42 Da from Drosophila melanogaster. BMC Struct Biol 14, 14.

Emsley, P., Lohkamp, B., Scott, W.G., and Cowtan, K. (2010). Features and development of Coot. Acta Crystallogr, Sect D: Biol Crystallogr 66, 486-501.

Engh, R., Löbermann, H., Schneider, M., Wiegand, G., Huber, R., and Laurell, C.B. (1989). The S variant of human alpha 1-antitrypsin, structure and implications for function and metabolism. Protein Eng 2, 407-415.

Eriksson, S., Carlson, J., and Velez, R. (1986). Risk of cirrhosis and primary liver cancer in alpha 1-antitrypsin deficiency. N Engl J Med 314, 736-739.

Evans, P.R., and Murshudov, G.N. (2013). How good are my data and what is the resolution? Acta Crystallogr, Sect D: Biol Crystallogr 69, 1204-1214.

Gettins, P.G.W. (2002). Serpin structure, mechanism, and function. Chem Rev 102, 4751-4804.

Gils, A., Knockaert, I., and Declerck, P.J. (1996). Substrate behavior of plasminogen activator inhibitor- 1 is not associated with a lack of insertion of the reactive site loop. Biochemistry 35, $7474-7481$.

Gooptu, B., Hazes, B., Chang, W.S., Dafforn, T.R., Carrell, R.W., Read, R.J., and Lomas, D.A. (2000). Inactive conformation of the serpin alpha(1)-antichymotrypsin indicates two-stage insertion of the reactive loop: implications for inhibitory function and conformational disease. Proc Natl Acad Sci USA 97, 67-72.

Goujon, M., McWilliam, H., Li, W., Valentin, F., Squizzato, S., Paern, J., and Lopez, R. (2010). A new bioinformatics analysis tools framework at EMBL-EBI. Nucleic Acids Res 38, W695-9. 
Hansen, M., Busse, M.N., and Andreasen, P.A. (2001). Importance of the amino-acid composition of the shutter region of plasminogen activator inhibitor-1 for its transitions to latent and substrate forms. Eur J Biochem 268, 6274-6283.

Harrop, S.J., Jankova, L., Coles, M., Jardine, D., Whittaker, J.S., Gould, A.R., Meister, A., King, G.C., Mabbutt, B.C., and Curmi, P.M. (1999). The crystal structure of plasminogen activator inhibitor 2 at 2.0 A resolution: implications for serpin function. Structure 7, 43-54.

Heiker, J.T. (2014). Vaspin (serpinA12) in obesity, insulin resistance, and inflammation. J Pept Sci 20, 299-306.

Heiker, J.T., Klöting, N., Kovacs, P., Kuettner, E.B., Sträter, N., Schultz, S., Kern, M., Stumvoll, M., Blüher, M., and Beck-Sickinger, A.G. (2013). Vaspin inhibits kallikrein 7 by serpin mechanism. Cell Mol Life Sci 70, 2569-2583.

Hida, K., Wada, J., Eguchi, J., Zhang, H., Baba, M., Seida, A., Hashimoto, I., Okada, T., Yasuhara, A., Nakatsuka, A., Shikata, K., Hourai, S., Futami, J., Watanabe, E., Matsuki, Y., Hiramatsu, R., Akagi, S., Makino, H., and Kanwar, Y.S. (2005). Visceral adipose tissue-derived serine protease inhibitor: a unique insulin-sensitizing adipocytokine in obesity. Proc Natl Acad Sci USA 102, 10610-10615.

Holm, L., and Rosenström, P. (2010). Dali server: conservation mapping in 3D. Nucleic Acids Res 38, W545-9.

Hopkins, P.C., Carrell, R.W., and Stone, S.R. (1993). Effects of mutations in the hinge region of serpins. Biochemistry 32, 7650-7657.

Huang, X., Yan, Y., TU, Y., Gatti, J., Broze, G.J.J., Zhou, A., and Olson, S.T. (2012). Structural Basis for Catalytic Activation of Protein Z-Dependent Protease Inhibitor (Zpi) by Protein Z. Blood $120,1726$.

Huber, R., and Carrell, R.W. (1989). Implications of the three-dimensional structure of alpha.1antitrypsin for structure and function of serpins. Biochemistry 28, 8951-8966.

Huntington, J.A., Kjellberg, M., and Stenflo, J. (2003). Crystal structure of protein C inhibitor provides insights into hormone binding and heparin activation. Structure 11, 205-215.

Huntington, J.A., Read, R.J., and Carrell, R.W. (2000). Structure of a serpin-protease complex shows inhibition by deformation. Nature 407, 923-926.

Huntington, J.A., Pannu, N.S., Hazes, B., Read, R.J., Lomas, D.A., and Carrell, R.W. (1999). A 2.6 A structure of a serpin polymer and implications for conformational disease. J Mol Biol 293, 449-455.

Jallat, S., Carvallo, D., Tessier, L.H., Roecklin, D., Roitsch, C., Ogushi, F., Crystal, R.G., and Courtney, M. (1986). Altered specificities of genetically engineered alpha 1 antitrypsin variants. Protein Eng 1, 29-35. 
Jankova, L., Harrop, S.J., Saunders, D.N., Andrews, J.L., Bertram, K.C., Gould, A.R., Baker, M.S., and Curmi, P.M. (2001). Crystal structure of the complex of plasminogen activator inhibitor 2 with a peptide mimicking the reactive center loop. J Biol Chem 276, 43374-43382.

Jensen, J.K., Thompson, L.C., Bucci, J.C., Nissen, P., Gettins, P.G.W., Peterson, C.B., Andreasen, P.A., and Morth, J.P. (2011). Crystal structure of plasminogen activator inhibitor-1 in an active conformation with normal thermodynamic stability. J Biol Chem 286, 29709-29717.

Jensen, J.K., and Gettins, P.G.W. (2008). High-resolution structure of the stable plasminogen activator inhibitor type-1 variant 14-1B in its proteinase-cleaved form: a new tool for detailed interaction studies and modeling. Protein Sci 17, 1844-1849.

Jeppsson, J.-O. (1976). Amino acid substitution Glu $\rightarrow$ Lys in $\alpha 1$-antitrypsin PiZ. FEBS Lett 65, 195-197.

Kabsch, W. (2010). XDS. Acta Crystallogr, Sect D: Biol Crystallogr 66, 125-132.

Kabsch, W., and Sander, C. (1983). Dictionary of protein secondary structure: pattern recognition of hydrogen-bonded and geometrical features. Biopolymers 22, 2577-2637.

Khan, M.S., Singh, P., Azhar, A., Naseem, A., Rashid, Q., Kabir, M.A., and Jairajpuri, M.A. (2011). Serpin Inhibition Mechanism: A Delicate Balance between Native Metastable State and Polymerization. J Amino Acids 2011, 606797.

Kirkegaard, T., Jensen, S., Schousboe, S.L., Petersen, H.H., Egelund, R., Andreasen, P.A., and Rodenburg, K.W. (1999). Engineering of conformations of plasminogen activator inhibitor-1. A crucial role of beta-strand $5 \mathrm{~A}$ residues in the transition of active form to latent and substrate forms. Eur J Biochem 263, 577-586.

Klöting, N., Berndt, J., Kralisch, S., Kovacs, P., Fasshauer, M., Schön, M.R., Stumvoll, M., and Blüher, M. (2006). Vaspin gene expression in human adipose tissue: association with obesity and type 2 diabetes. Biochem Biophys Res Com 339, 430-436.

Lee, C., Park, S.-H., Lee, M.-Y., and Yu, M.-H. (2000). Regulation of protein function by native metastability. Proc Natl Acad Sci USA 97, 7727-7731.

Li, J., Wang, Z., Canagarajah, B., Jiang, H., Kanost, M., and Goldsmith, E.J. (1999). The structure of active serpin 1K from Manduca sexta. Structure 7, 103-109.

Li, W., and Huntington, J.A. (2008). The heparin binding site of protein C inhibitor is proteasedependent. J Biol Chem 283, 36039-36045.

Li, W., Adams, T.E., Kjellberg, M., Stenflo, J., and Huntington, J.A. (2007). Structure of native protein C inhibitor provides insight into its multiple functions. J Biol Chem 282, 13759-13768.

Lomas, D.A., and Carrell, R.W. (2002). Serpinopathies and the conformational dementias. Nat Rev Genet 3, 759-768. 
Lomas, D.A., Elliott, P.R., Chang, W.S., Wardell, M.R., and Carrell, R.W. (1995). Preparation and characterization of latent alpha 1-antitrypsin. J Biol Chem 270, 5282-5288.

Lomas, D.A., Evans, D.L., Finch, J.T., and Carrell, R.W. (1992). The mechanism of Z alpha 1antitrypsin accumulation in the liver. Nature 357, 605-607.

Lukacs, C.M., Rubin, H., and Christianson, D.W. (1998a). Engineering an anion-binding cavity in antichymotrypsin modulates the "spring-loaded" serpin-protease interaction. Biochemistry 37, 3297-3304.

Lukacs, C.M., Rubin, H., and Christianson, D.W. (1998b). Engineering an anion-binding cavity in antichymotrypsin modulates the "spring-loaded" serpin-protease interaction. Biochemistry 37, 3297-3304.

McCoy, A.J., Grosse-Kunstleve, R.W., Adams, P.D., Winn, M.D., Storoni, L.C., and Read, R.J. (2007). Phaser crystallographic software. J Appl Crystallogr 40, 658-674.

Millar, D.S., Wacey, A.I., Ribando, J., Melissari, E., Laursen, B., Woods, P., Kakkar, V.V., and Cooper, D.N. (1994). Three novel missense mutations in the antithrombin III (AT3) gene causing recurrent venous thrombosis. Hum Genet 94, 509-512.

Molho-Sabatier, P., Aiach, M., Gaillard, I., Fiessinger, J.N., Fischer, A.M., Chadeuf, G., and Clauser, E. (1989). Molecular characterization of antithrombin III (ATIII) variants using polymerase chain reaction. Identification of the ATIII Charleville as an Ala 384 Pro mutation. J Clin Invest 84, 1236-1242.

Mottonen, J., Strand, A., Symersky, J., Sweet, R.M., Danley, D.E., Geoghegan, K.F., Gerard, R.D., and Goldsmith, E.J. (1992). Structural basis of latency in plasminogen activator inhibitor-1. Nature $355,270-273$.

Murshudov, G.N., Skubák, P., Lebedev, A.A., Pannu, N.S., Steiner, R.A., Nicholls, R.A., Winn, M.D., Long, F., and Vagin, A.A. (2011). REFMAC5 for the refinement of macromolecular crystal structures. Acta Crystallogr, Sect D: Biol Crystallogr 67, 355-367.

Murshudov, G.N., Vagin, A.A., and Dodson, E.J. (1997). Refinement of macromolecular structures by the maximum-likelihood method. Acta Crystallogr, Sect D: Biol Crystallogr 53, 240-255.

Nakatsuka, A., Wada, J., Iseda, I., Teshigawara, S., Higashio, K., Murakami, K., Kanzaki, M., Inoue, K., Terami, T., Katayama, A., Hida, K., Eguchi, J., Horiguchi, C.S., Ogawa, D., Matsuki, Y., Hiramatsu, R., Yagita, H., Kakuta, S., Iwakura, Y., and Makino, H. (2012). Vaspin is an adipokine ameliorating ER stress in obesity as a ligand for cell-surface GRP78/MTJ-1 complex. Diabetes 61, 2823-2832.

Na, Y.-R., and Im, H. (2007). Specific interactions of serpins in their native forms attenuate their conformational transitions. Protein Sci 16, 1659-1666.

Oliveira, J.R., Bertolin, T.C., Andrade, D., Oliveira, L.C.G., Kondo, M.Y., Santos, J.A.N., Blaber, M., Juliano, L., Severino, B., Caliendo, G., Santagada, V., and Juliano, M.A. (2015). Specificity 
studies on Kallikrein-related peptidase 7 (KLK7) and effects of osmolytes and glycosaminoglycans on its peptidase activity. Biochim Biophys Acta 1854, 73-83.

Painter, J., and Merritt, E.A. (2006a). Optimal description of a protein structure in terms of multiple groups undergoing TLS motion. Acta Crystallogr, Sect D: Biol Crystallogr 62, 439-450.

Painter, J., and Merritt, E.A. (2006b). TLSMD web server for the generation of multi-group TLS models. J Appl Crystallogr 39, 109-111.

Patston, P.A., Gettins, P., Beechem, J., and Schapira, M. (1991). Mechanism of serpin action. Evidence that $\mathrm{C} 1$ inhibitor functions as a suicide substrate. Biochemistry 30, 8876-8882.

Pearce, M.C., Morton, C.J., Feil, S.C., Hansen, G., Adams, J.J., Parker, M.W., and Bottomley, S.P. (2008). Preventing serpin aggregation: the molecular mechanism of citrate action upon antitrypsin unfolding. Protein Sci 17, 2127-2133.

Pearce, M.C., Cabrita, L.D., Ellisdon, A.M., and Bottomley, S.P. (2007). The loss of tryptophan 194 in antichymotrypsin lowers the kinetic barrier to misfolding. FEBS J 274, 3622-3632.

Perry, D.J., Harper, P.L., Fairham, S., Daly, M., and Carrell, R.W. (1989). Antithrombin Cambridge, 384 Ala to Pro: a new variant identified using the polymerase chain reaction. FEBS Lett 254, 174-176.

Ricagno, S., Caccia, S., Sorrentino, G., Antonini, G., and Bolognesi, M. (2009). Human neuroserpin: structure and time-dependent inhibition. J Mol Biol 388, 109-121.

Robert, X., and Gouet, P. (2014). Deciphering key features in protein structures with the new ENDscript server. Nucleic Acids Res 42, W320-4.

Ryu, S.-E., Choi, H.-J., Kwon, K.-S., Lee, K.N., and Yu, M.-H. (1996). The native strains in the hydrophobic core and flexible reactive loop of a serine protease inhibitor. Crystal structure of an uncleaved $\alpha 1$-antitrypsin at 2.7 å. Structure 4, 1181-1192.

Saalbach, A., Vester, K., Rall, K., Tremel, J., Anderegg, U., Beck-Sickinger, A.G., Blüher, M., and Simon, J.C. (2012). Vaspin - a link of obesity and psoriasis? Exp Dermatol 21, 309-312.

Saunders, D.N., Jankova, L., Harrop, S.J., Curmi, P.M., Gould, A.R., Ranson, M., and Baker, M.S. (2001). Interaction between the P14 residue and strand 2 of beta-sheet B is critical for reactive center loop insertion in plasminogen activator inhibitor-2. J Biol Chem 276, 43383-43389.

Schechter, I., and Berger, A. (1967). On the size of the active site in proteases. I. Papain. Biochem Biophys Res Commun 27, 157-162.

Schreuder, H.A., Boer, B. de, Dijkema, R., Mulders, J., Theunissen, H.J., Grootenhuis, P.D., and Hol, W.G. (1994). The intact and cleaved human antithrombin III complex as a model for serpinproteinase interactions. Nat Struct Biol 1, 48-54. 
Schultz, S., Saalbach, A., Heiker, J.T., Meier, R., Zellmann, T., Simon, J.C., and Beck-Sickinger, A.G. (2013). Proteolytic activation of prochemerin by kallikrein 7 breaks an ionic linkage and results in C-terminal rearrangement. Biochem J 452, 271-280.

Seyama, K., Nukiwa, T., Takabe, K., Takahashi, H., Miyake, K., and Kira, S. (1991). Siiyama (serine 53 (TCC) to phenylalanine 53 (TTC)). A new alpha 1-antitrypsin-deficient variant with mutation on a predicted conserved residue of the serpin backbone. J Biol Chem 266, 12627-12632.

Sharp, A.M., Stein, P.E., Pannu, N.S., Carrell, R.W., Berkenpas, M.B., Ginsburg, D., Lawrence, D.A., and Read, R.J. (1999). The active conformation of plasminogen activator inhibitor 1, a target for drugs to control fibrinolysis and cell adhesion. Structure 7, 111-118.

Sievers, F., Wilm, A., Dineen, D., Gibson, T.J., Karplus, K., Li, W., Lopez, R., McWilliam, H., Remmert, M., Söding, J., Thompson, J.D., and Higgins, D.G. (2011). Fast, scalable generation of high-quality protein multiple sequence alignments using Clustal Omega. Mol Syst Biol 7, 539.

Stein, P.E., and Carrell, R.W. (1995). What do dysfunctional serpins tell us about molecular mobility and disease? Nat Struct Biol 2, 96-113.

Stoller, J.K., and Aboussouan, L.S. (2012). A review of $\alpha 1$-antitrypsin deficiency. Am J Respir Crit Care Med 185, 246-259.

Stout, T.J., Graham, H., Buckley, D.I., and Matthews, D.J. (2000). Structures of Active and Latent PAI-1. A Possible Stabilizing Role for Chloride Ions $\ddagger$. Biochemistry 39, 8460-8469.

Takao, M., Benson, M.D., Murrell, J.R., Yazaki, M., Piccardo, P., Unverzagt, F.W., Davis, R.L., Holohan, P.D., Lawrence, D.A., Richardson, R., Farlow, M.R., and Ghetti, B. (2000). Neuroserpin mutation S52R causes neuroserpin accumulation in neurons and is associated with progressive myoclonus epilepsy. J Neuropathol Exp Neurol 59, 1070-1086.

Takehara, S., Onda, M., Zhang, J., Nishiyama, M., Yang, X., Mikami, B., and Lomas, D.A. (2009). The 2.1-A crystal structure of native neuroserpin reveals unique structural elements that contribute to conformational instability. J Mol Biol 388, 11-20.

Touw, W.G., Baakman, C., Black, J., te Beek, Tim A H, Krieger, E., Joosten, R.P., and Vriend, G. (2015). A series of PDB-related databanks for everyday needs. Nucleic Acids Res 43, D364-8.

Ulbricht, D., Pippel, J., Schultz, S., Meier, R., Sträter, N., and Heiker, J.T. (2015). A unique serpin $\mathrm{P} 1$ ' glutamate and a conserved $\beta$-sheet $\mathrm{C}$ arginine are key residues for activity, protease recognition and stability of serpinA12 (vaspin). Biochem J 470, 357-367.

Wardell, M.R., Chang, W.S., Bruce, D., Skinner, R., Lesk, A.M., and Carrell, R.W. (1997). Preparative induction and characterization of L-antithrombin: a structural homologue of latent plasminogen activator inhibitor-1. Biochemistry 36, 13133-13142.

Whisstock, J.C., Skinner, R., Carrell, R.W., and Lesk, A.M. (2000). Conformational changes in serpins: I. The native and cleaved conformations of alpha(1)-antitrypsin. J Mol Biol 295, 651-665. 
Yamasaki, M., Sendall, T.J., Pearce, M.C., Whisstock, J.C., and Huntington, J.A. (2011). Molecular basis of $\alpha 1$-antitrypsin deficiency revealed by the structure of a domain-swapped trimer. EMBO reports 12, 1011-1017.

Yamasaki, M., Li, W., Johnson, D.J.D., and Huntington, J.A. (2008). Crystal structure of a stable dimer reveals the molecular basis of serpin polymerization. Nature 455, 1255-1258.

Youn, B.-S., Klöting, N., Kratzsch, J., Lee, N., Park, J.W., Song, E.-S., Ruschke, K., Oberbach, A., Fasshauer, M., Stumvoll, M., and Blüher, M. (2008). Serum vaspin concentrations in human obesity and type 2 diabetes. Diabetes $57,372-377$.

Zhou, A., Stein, P.E., Huntington, J.A., and Carrell, R.W. (2003). Serpin polymerization is prevented by a hydrogen bond network that is centered on his-334 and stabilized by glycerol. $\mathrm{J}$ Biol Chem 278, 15116-15122.

Zhou, A., Faint, R., Charlton, P., Dafforn, T.R., Carrell, R.W., and Lomas, D.A. (2001). Polymerization of plasminogen activator inhibitor-1. J Biol Chem 276, 9115-9122. 
Table 1: Crystal structures of cleaved human serpins with rmsd values and sequence identities towards the cleaved vaspin structure

\begin{tabular}{|c|c|c|c|c|}
\hline Serpin name & pdb code & $\begin{array}{c}\text { rmsd } \\
{[\AA \AA]}\end{array}$ & $\begin{array}{c}\text { sequence } \\
\text { identity [\%] }\end{array}$ & references \\
\hline \multirow{5}{*}{ 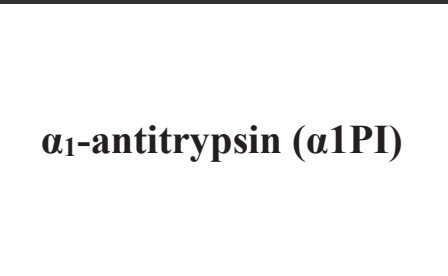 } & 1QMB & 1.5 & 43 & Huntington et al., 1999 \\
\hline & 7API & 1.7 & 41 & \multirow{3}{*}{ Engh et al., 1989} \\
\hline & 8API & 1.6 & 41 & \\
\hline & 9API & 1.6 & 41 & \\
\hline & $3 \mathrm{NDF}$ & 1.4 & 42 & Yamasaki et al., 2008 \\
\hline \multirow{2}{*}{$\begin{array}{l}\text { plasminogen activator } \\
\text { inhibitor-1 (PAI-1) }\end{array}$} & $3 \mathrm{EOX}$ & 2.0 & 24 & Dewilde et al., 2009 \\
\hline & $3 \mathrm{CVM}$ & 2.1 & 24 & Jensen and Gettins, 2008 \\
\hline \multirow{2}{*}{ protein $\mathrm{C}$ inhibitor (PCI) } & 1LQ8 & 1.3 & 40 & Huntington et al., 2003 \\
\hline & $3 \mathrm{DY} 0$ & 1.5 & 40 & Li and Huntington, 2008 \\
\hline \multirow{3}{*}{$\begin{array}{c}\alpha_{1} \text {-antichymotrypsin } \\
(\alpha 1 \mathrm{ACT})\end{array}$} & $2 \mathrm{ACH}$ & 1.3 & 39 & Baumann et al., 1991 \\
\hline & $1 \mathrm{AS} 4$ & 1.4 & 38 & \multirow{2}{*}{ Lukacs et al., 1998b } \\
\hline & 4CAA & 1.3 & 38 & \\
\hline antithrombin ( $\alpha 1 \mathrm{AT})$ & $1 \mathrm{ATH}$ & 2.0 & 31 & Schreuder et al., 1994 \\
\hline \multirow{2}{*}{$\begin{array}{c}\text { protein Z-dependent } \\
\text { protease inhibitor (PZI) }\end{array}$} & $4 \mathrm{AFX}$ & 1.9 & 29 & \multirow{2}{*}{ Huang et al., 2012} \\
\hline & 4AJU & 2.0 & 29 & \\
\hline neuroserpin & $3 \mathrm{~F} 02$ & 1.6 & 27 & Ricagno et al., 2009 \\
\hline
\end{tabular}




\section{Figure legends}

Figure 1: Comparison of native and cleaved vaspin. (A) Superposition of the cleaved (light blue and dark red) and native (yellow) vaspin crystal structures. In the cleaved state, the RCL (E362M378; dark red) incorporates as additional $\beta$-strand into the central $\beta$-sheet. (B) Vaspin most likely was cleaved between P1 (M378) and P1' (E379) as apparent from the electron density of the feature enhanced map $(2 \sigma)$ in chain B. Probably due to their increased flexibility, residues E379 and T380 could not be modeled in this chain.

Figure 2: Conserved amino acids in the shutter region of the native (A) and the cleaved vaspin crystal structure (B). Feature enhanced maps are displayed as red mesh contoured at $2 \sigma$ with hydrogen bonds depicted as black dashed lines.

Figure 3: Multiple sequence alignment and consensus sequence of human inhibitory serpins for selected amino acids. The sequence numbering corresponds to human vaspin and the scissile bond located between P1 and P1' is highlighted by scissors. Sequences were aligned using the Clustal Omega algorithm at EMBL-EBI. The alignment was generated with ESPript 3.0 and manually edited.

Figure 4: Overview of interactions within the breach region and of the breach region with the RCL hinge residues (D362-G370, P17-P9 in the native (A; pdb code: 4IF8) and cleaved vaspin (B) Xray structure. Residues of the RCL hinge region are shown in light-blue. Important residues of the breach domain are colored in yellow. The groove is depicted as grey surface.

Figure 5: Thermo-stability substrate mutants (cleaved and uncleaved) as well as heat-induced polymerization of vaspin. (A) Thermal unfolding of non-inhibitory mutants T365R and A369P from single samples observed by far-UV CD at $208 \mathrm{~nm}$ at a heating rate of $50^{\circ} \mathrm{C} / \mathrm{h}$ (in phosphate buffer, $\mathrm{pH} 7.8,1.5 \mu \mathrm{M})$. The shift to higher temperatures for unfolding suggests RCL insertion 
resulted in the hyperstable conformation. (B) SDS-PAGE analysis of polymerization for noninhibitory mutants $\mathrm{T} 365 \mathrm{R}$ and $\mathrm{A} 369 \mathrm{P}$ in native and cleaved state after 60 min incubation at indicated temperatures ( $\mathrm{RT}$ - room temperature). Taken together with the $\mathrm{CD}$ data in $(\mathrm{A})$, this demonstrates RCL insertion for both hinge region mutants after cleavage. P10 proline slightly destabilizes the relaxed (cleaved) state. (C) SDS-PAGE analysis of vaspin polymerization (top) and complex formation (bottom) after $3 \mathrm{~h}$ incubation at indicated temperatures with different $\mathrm{NaCl}$ and citrate concentrations (a: $0 \mathrm{mM} \mathrm{NaCl}, 0 \mathrm{mM}$ citrate; b: $500 \mathrm{mM} \mathrm{NaCl}, 0 \mathrm{mM}$ citrate; c: $0 \mathrm{mM}$ $\mathrm{NaCl}, 850 \mathrm{mM}$ citrate; d: $500 \mathrm{mM} \mathrm{NaCl}, 850 \mathrm{mM}$ citrate). (D) SDS-PAGE analysis as in (C) but after prolonged $15 \mathrm{~h}$ incubation at indicated temperatures (as in d: $500 \mathrm{mM} \mathrm{NaCl}, 850 \mathrm{mM}$ citrate). While citrate suppressed polymerization, the monomeric vaspin remains active and able to inhibit KLK7. Indicated bands are: 1 - serpin-protease complex; 2 - active serpin; 3 - active, Tag-cleaved serpin; 4 - cleaved serpin; 5 - protease. 
Figure 1

A

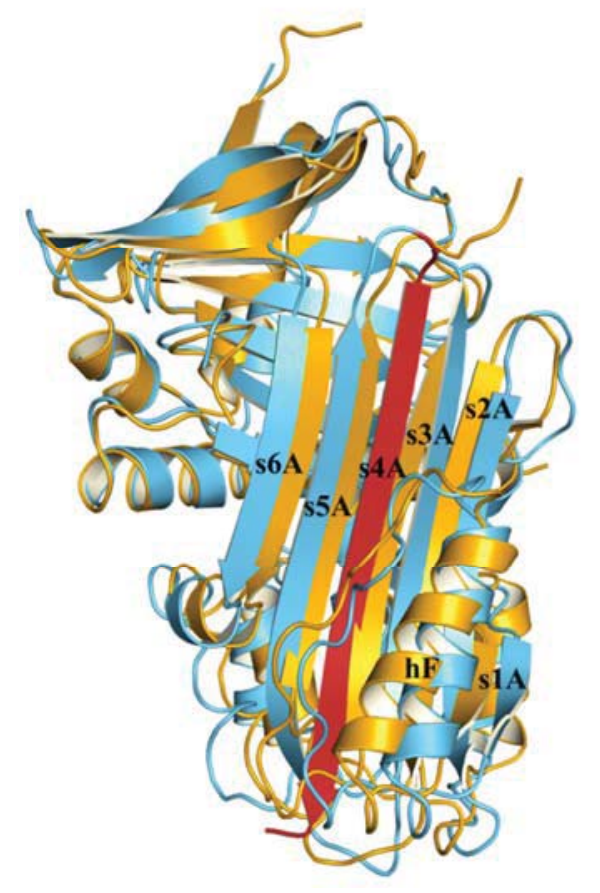

B

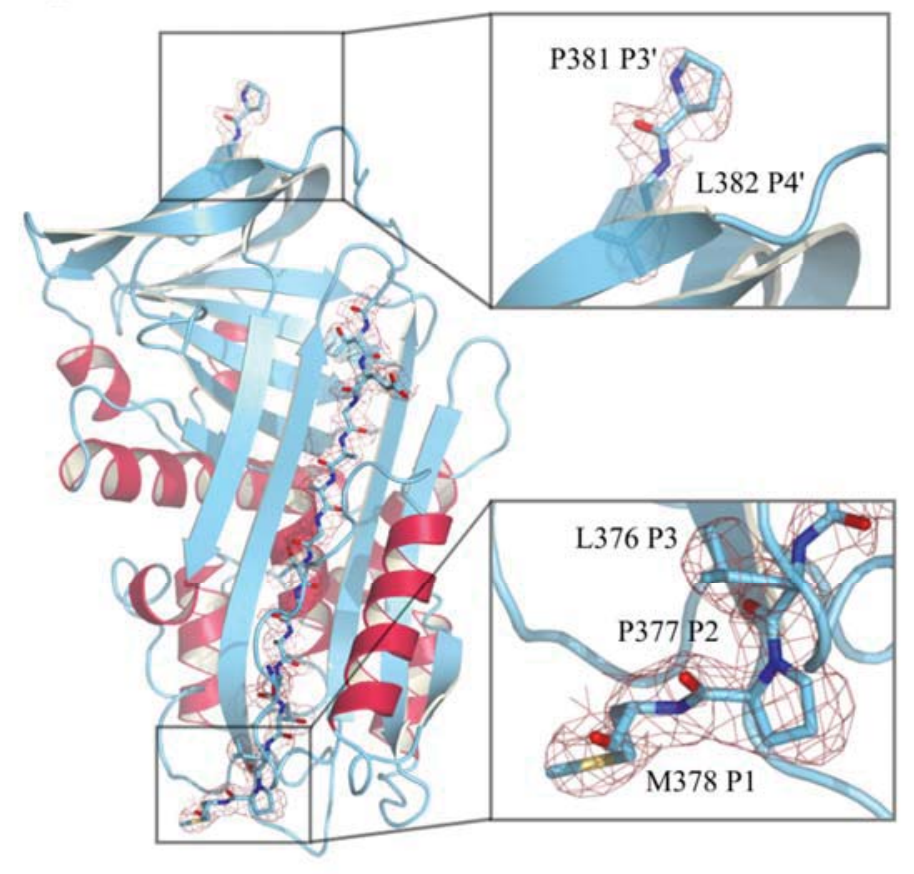




\section{Figure 2}

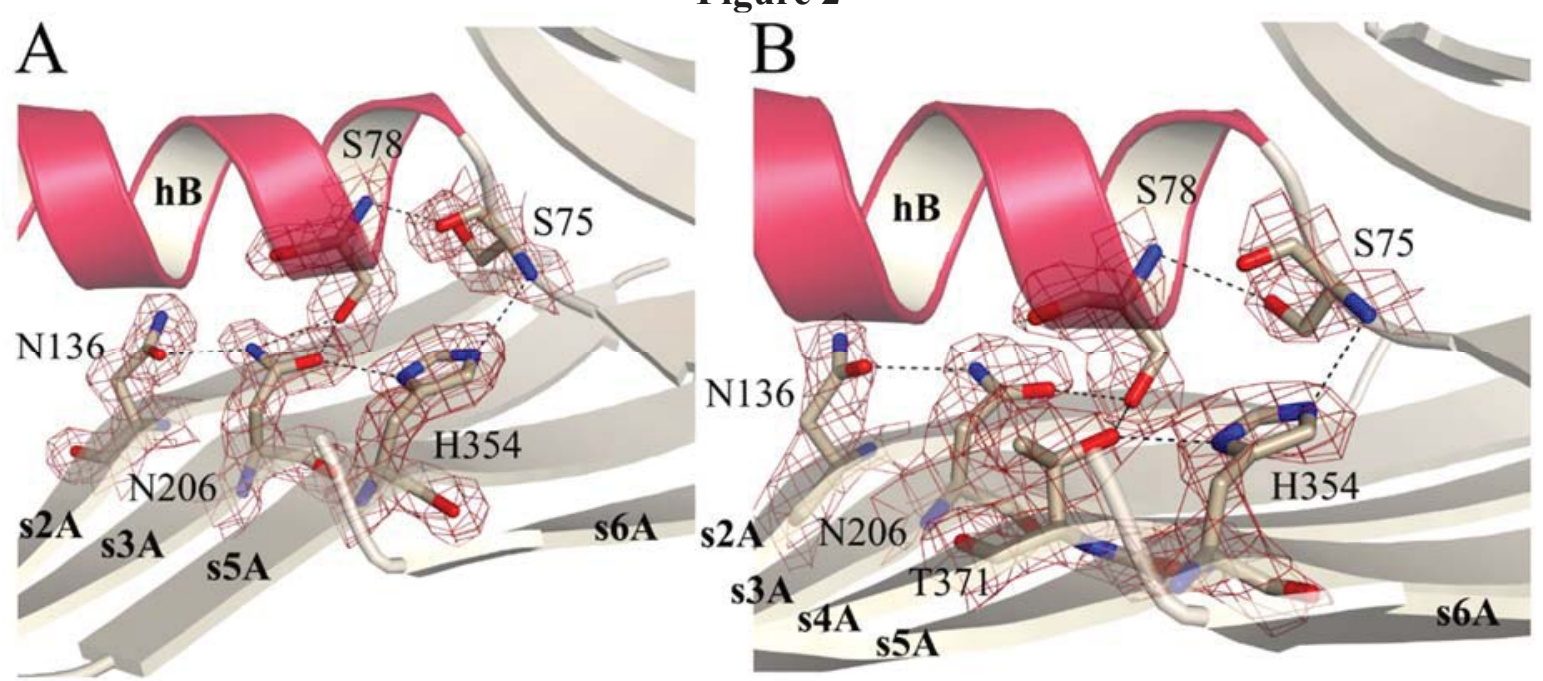




\section{Figure 3}

\section{5}

A12; Vasp

$\mathrm{A} 1 ; \alpha_{1} \mathrm{PI}$

$\mathrm{A} 3 ; \alpha_{1}-\mathrm{ACT}$

A4; kallistatin
A5; $\mathrm{PCl}$

A9; centerin

$\mathrm{B} 1$; $\mathrm{MNEI}$
$\mathrm{B} 2$; PAI-2

B3; SCCA1

B4; $\mathrm{SCCA} 2$

B6; P16
B7; megsin
B8; PI8

B9; PI9

B10; bomapi

${ }_{\mathrm{B} 12}^{\mathrm{B} 11}$; epipin

B13; headpin

$\mathrm{Cl}$; antithrombin

E1; heparin cofactor

E2; protease nexin 1

F2; $a_{\text {2antiplasmin }}$
G1; C1-inhibitor

II; neuroserpin

consensus sequence 70

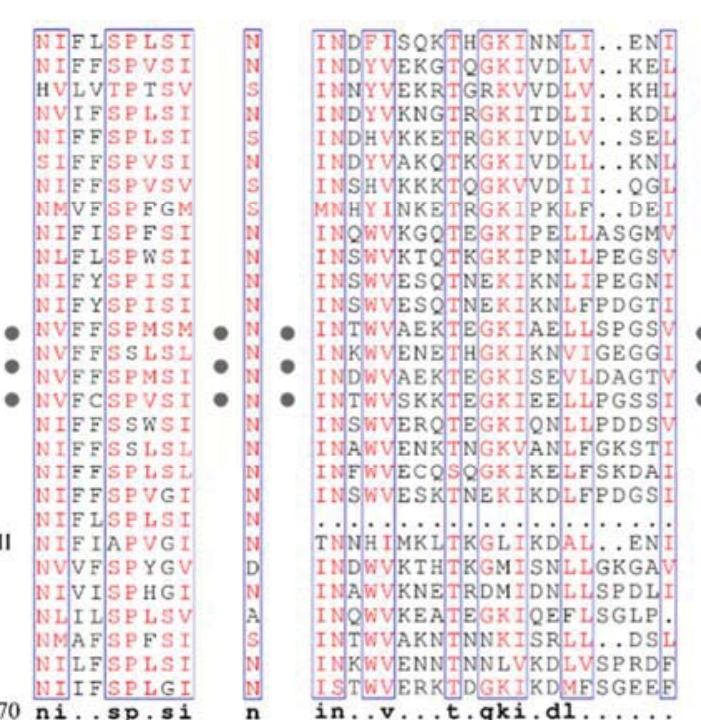

in..v..t. $\mathrm{tki} \cdot \mathrm{dl}$.....
(

TVWLLAMY IFFRARWRHEFDP

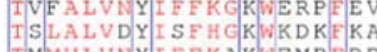

TMMVLVNY Y FFKAKWEMPFDP

AVVIMVMYIFFKAKWETSENH
TAMVLVNHIFFKAKWEKPFHP

IKL I I LVDY I LFK K KW WL T PEDP

IRMVLVNA VYFKGKWKTPEEK

M A I YFKGOWENKFKK

- AVMVLVNAVYFKGKWOSAETK

- TRLVLVHA YYFKGKWNEPFDE

1RMILVAALYFRGIWEHQELV

TVLVLVNAVYFKAKWETYFD

TKLVLVHMVYFKGOWDREFK KK

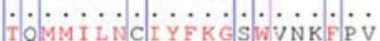

RLVLVMALYFNGOWKTPFPD

LVNAVYFKGLWKSRFOP

IVLLLLAAI HFQGFWRNKEDP

TLALI INAVYF K GNWK SQFRE

$\mathrm{t}, 1 \mathrm{vivn}, i \mathrm{ffkg}, \mathrm{f}$
$264 \quad 310$

VPRIHVTT I.PKLS

IPKFES

IPKFSIS
IPKFSIIE

FPKFK LD

IPQFKLE
IPRFKUE

DPRFKIE

- FPQFKIE

- IPKFKLQ

IPKFKIE

FPRFTLE
LPRFEVE

….

IPKFKLE

LPKFTAV

IPKLYLK

IPRIKVI

$\frac{L P R F K U E}{1 \mathrm{P}, \mathrm{f}}$
$360 \quad 370 \quad 380$

P15 $13119876543211^{\prime 2} 2^{\prime}$ HMAEL KMDERTEGAAGTGAQTLPMETP HVAVITIDEKGTEATGAPHLEEKAWSKY HAVIDVREEGTEASAATAVKITILSALV HKATLDVDEAGTEAAAATSEAIKFF SAQT AKA VVEVDESGIRAAAAI GT IFTFRSAR. 2ETVISVDER TEAYAGI SEITAYSYPP RSF EONDETTEAAAATAOIATFCMLMP QAMVDVNEEGTEAAAG TGGVMTGRTGHG AFVEVTEEGVEAAAATAVVVVELSSPS HNSYEVTEEGTEATAATGSNIVEKOIPQ HKFVEVNEEGIEAAAA TAVVRNSRCSRM HAFVEINEOGTEAAAGSGSEIDIRIRVP HRTFVEVDENGTOAAAATGAVYSERSLRS SSFVAVTEEGTEAAAAT GIGFTVTSAPG KAFLEVNEEGSAAASTAVVIAGRSLNP QXVITVUSTVASSSTAVTVSARM ONAKIEVSEDCTKASAATTAILIARSSP HOSTLELSEVGVEAAAATS. IAMSRMSLS HQTVLELTET GVEAAAASA. ISVARTLLV AWSFLEVNEE ESEAAAV SGMIAISRMAV

hk ev, E.Gteaaat t 
Figure 4

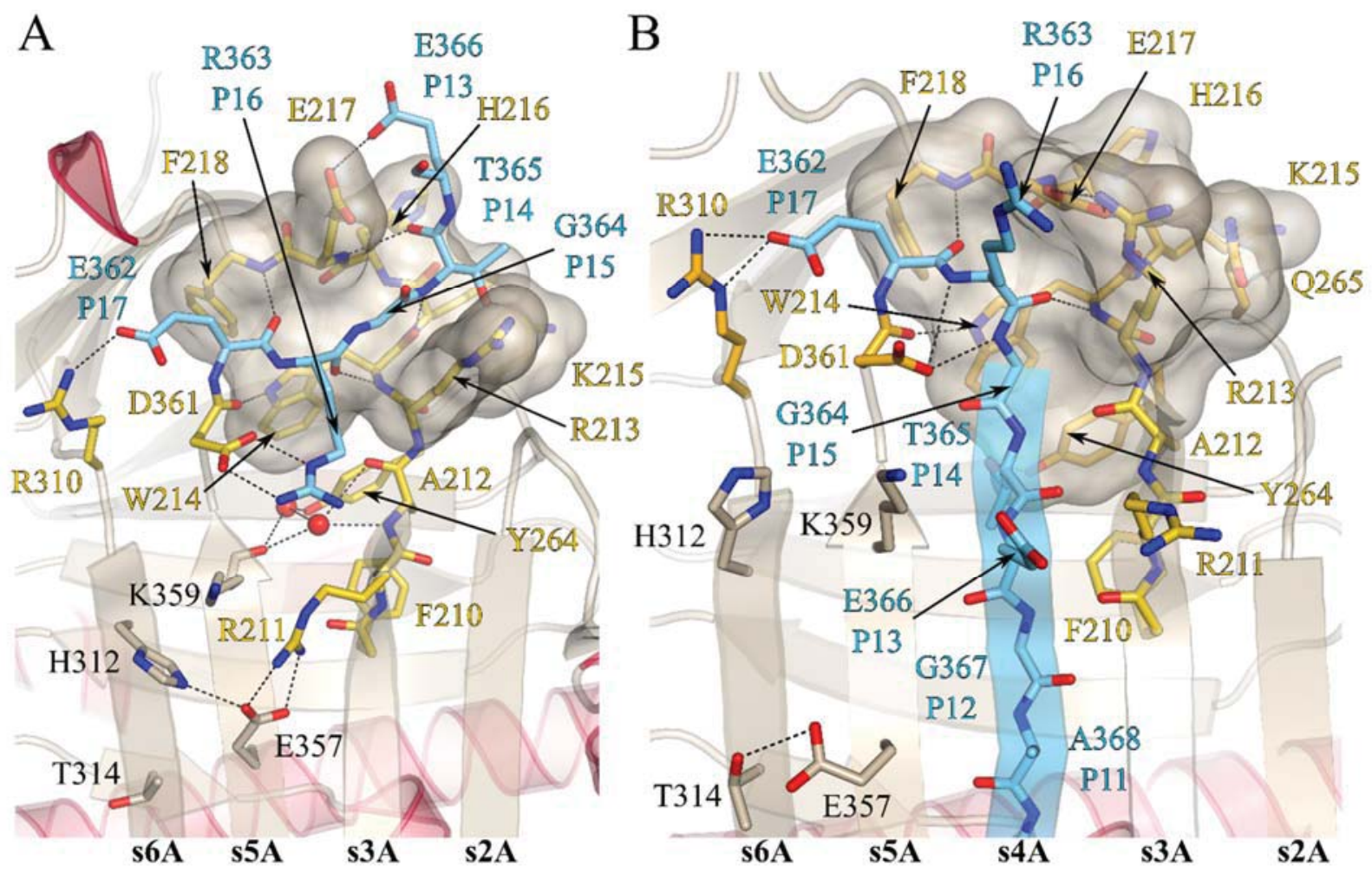


Figure 5

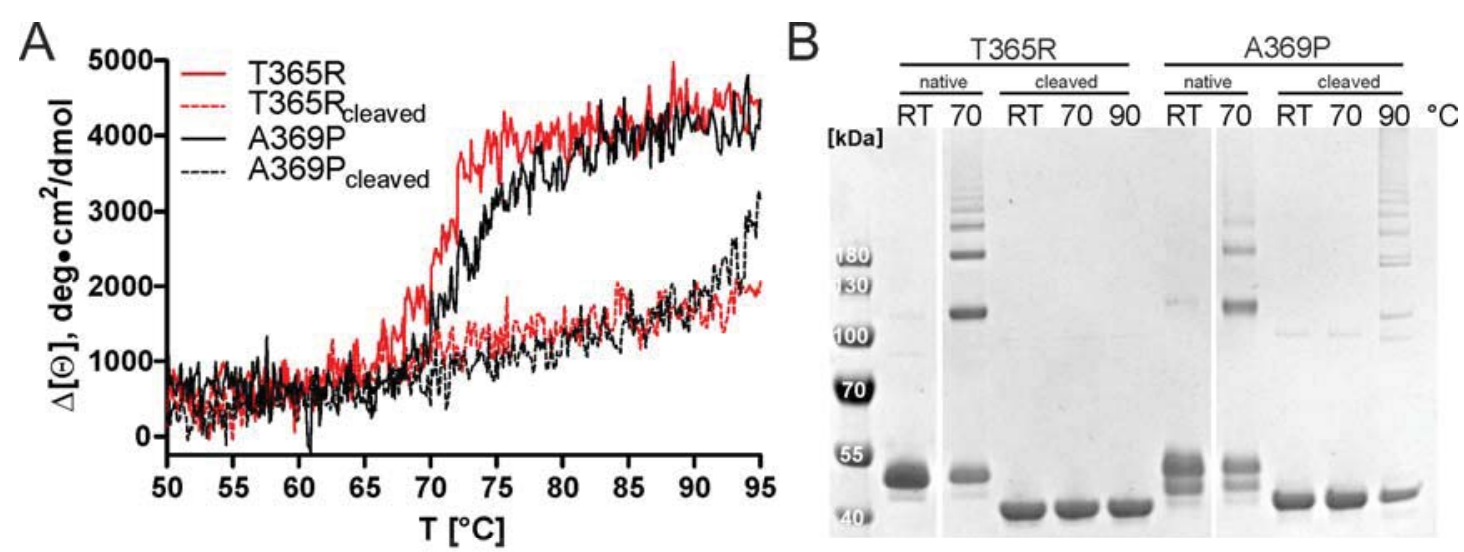

C

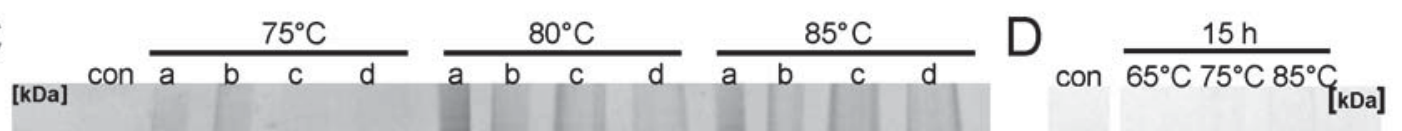

亭
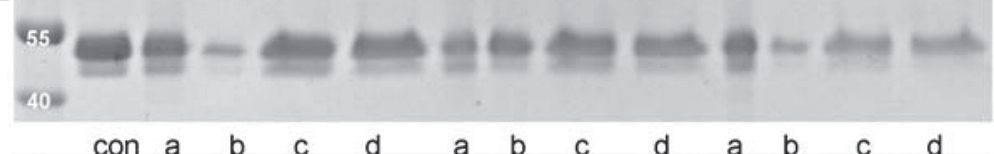

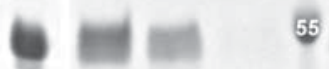

$\operatorname{con} 65^{\circ} \mathrm{C} 75^{\circ} \mathrm{C} 85^{\circ} \mathrm{C}$

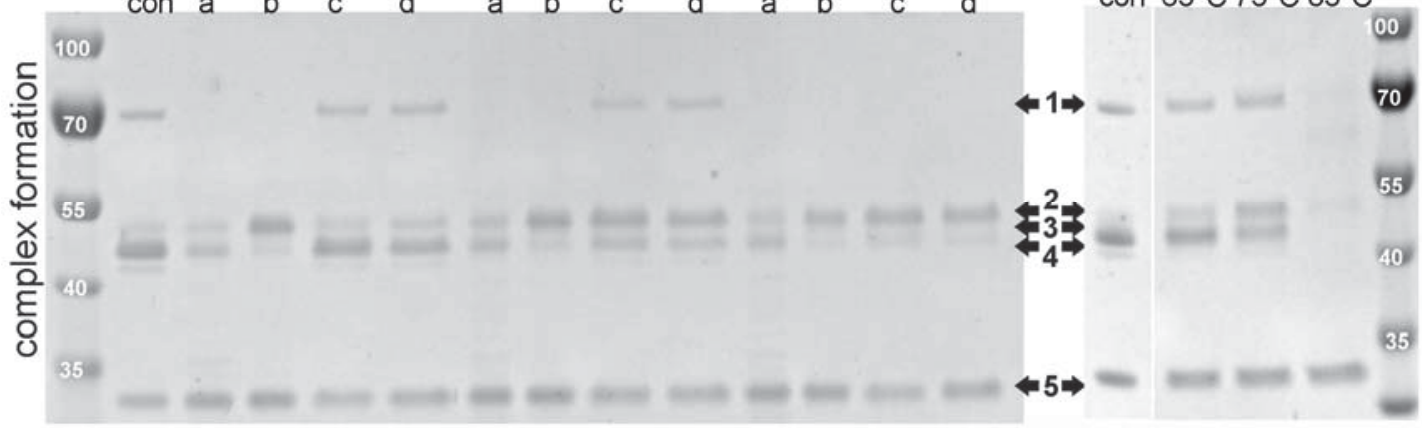

